\title{
Palabras del Decano
}

Discurso del Prof. Dr. Marcelo Yorio, Decano de la FCM UNC, en el Acto de Colación de egresados de la Carrera de Medicina, marzo 2016.

Autoridades presentes, Sres. Secretarios, Sub Secretarios y Directores de Escuelas de nuestra Facultad. Sres. Profesores, familiares de los colegas egresados, colegas, señoras y señores

Queridos egresados:

En nombre de la Facultad de Ciencias Médicas, tengo el honor de expresarles que nuestra casa se llena de júbilo, ante su evento más trascendente, la colación de sus egresados, dando marco a la culminación de una etapa de aprendizajes y experiencias, que se ven cristalizados en la obtención de este honrado Título que los distinguirá de ahora en más como Médicos.

Hoy, también es una fiesta, porque este imponente marco universitario se engalana con la presencia de vuestros seres queridos, familia y amigos, quienes por haberlos acompañado incondicionalmente, comparten hoy el mismo orgullo y satisfacción de haber alcanzado este logro tan importante, reconociendo implícitamente vuestro esfuerzo, pero también porque expresan el amor con que los han seguido en toda la etapa de estudiantes. Nuestra Facultad queridos familiares, también quiere agradecerles por vuestra confianza y por vuestra compañía. Muchas gracias.

La realidad actual de la Salud Pública argentina, encuentra varias encrucijadas en las cuales las facultades en ciencias de la salud se encuentran particularmente comprometidas, la gran extensión geográfica de nuestro país con múltiples diversidades geográficas, económicas y socioculturales, y una débil planificación desde hace décadas en la búsqueda de fortalecer el capital humano en salud, hacen que hoy éste recurso humano esté jaqueado. Así es conocido por todos, que existe escasez de médicos en muchas poblaciones pequeñas que aseguren una asistencia apropiada tanto en salud como ante una enfermedad. Pero más allá de los múltiples argumentos que pueden esgrimirse para explicar tan complejo problema, Argentina, según fuentes del Ministerio de Salud de la Nación cuenta hoy con 166000 médicos, con una tasa/mil habitantes de 3.9, lo que la ubica en el mundo entre los países con mejor cantidad de médicos por habitantes; o sea no nos faltan médicos, pero nuestro gran problema nacional es la distribución de los mismos en las diferentes regiones, con una concentración máxima en zonas de alta densidad poblacional, en contraste con muchas poblaciones pequeñas sin médicos. El otro gran problema en medicina que afrontamos, es la carencia en especialidades básicas, que son quienes pueden permitirnos llevar a cabo políticas nacionales en salud pública, en todos los sectores y en todas las regiones.

Creemos, que estas problemáticas tan acuciantes no podremos solucionarlas tan solo 
desde el ámbito académico, sino con una estrategia nacional orientando este capital humano, dotándolo de condiciones favorables para el asentamiento en diferentes lugares y el desarrollo de las especialidades básicas necesarias. Así, adscribimos absolutamente con la política de Atención Primaria de la Salud, lo cual consta fehacientemente en nuestros programas. Sólo si esta estrategia en salud es una política nacional, que abarque los diversos sectores de la salud, con la Atención Primaria como eje central, y en una estrategia a largo plazo; sólo así, se conseguirán sortear los problemas más críticos del sistema actual. Las facultades y universidades por sí solas, no podrán hacerlo.

Compartimos y defendemos absolutamente el concepto de inclusión que debe regir nuestro ámbito público y universitario, pero también creo en el pacto social que nuestras casas de estudio tienen, en la responsabilidad de la formación de excelencia de nuestros profesionales, por lo que alentamos también a una estrategia nacional de las instituciones públicas comprometidas en esta preparación, no puede ya, de ninguna manera imaginarse que algunas pocas facultades de medicina sean las formadoras de todo éste importante recurso. Por ello nuestra facultad ha alentado, trabajado consecuentemente y apoyado nuevas facultades de medicina públicas: La Rioja, Villa María, Santiago del Estero, Salta, Patagonia o Chaco, entre otras.

Estamos también muy comprometidos con la formación académica y profesional de nuestros egresados. Nuestra carrera debe garantizar a toda la comunidad que los recibe, las suficientes competencias profesionales exigibles para su ético y completo desarrollo; y esta condición debe cumplirse acabadamente a su egreso, porque nuestro título es de inmediato habilitante para el ejercicio de la medicina. Esto, no sólo significa "saber" o incluso "saber cómo", si no que las competencias deben asegurar el "saber hacer"; o sea el estudiante necesita de la práctica real de la medicina, con ciertos grados mínimos de habilidades adquiridas, tanto en los diferentes escenarios de la salud que existen, como de las diferentes técnicas comunicacionales y de examen, con que se abordará con idoneidad y responsabilidad su actividad profesional. Además, este trayecto pedagógico debe respetar a ultranza el marco ético de respeto, confidencialidad y privacidad hacia las personas que se asisten en nuestros diferentes ambientes de formación.

En este camino nuestra facultad, ha continuado una política enmarcada en gestionar académicamente la real capacidad de nuestros diversos espacios educativos, de modo que el ingresante tenga asegurado los ámbitos pertinentes e imprescindibles tanto en las áreas básicas, clínicas, como de la Práctica Final Obligatoria; de modo, que todo el recorrido de su formación tenga como objetivo un profesional cabal, experimentado y comprometido con el medio en el cual volcará sus conocimientos e intervenciones. En la actualidad, nuestra tasa de egreso representa un dato estadístico de gran relevancia y jerarquía académica: de las últimas 3 cohortes de egresados el $50 \%$ de los alumnos lo hacen a los 6 años, y el 75\% a los 6.5 años, cuando hace una década un importante número de alumnos estaba entre 10 y 11 años de cursada. El promedio final de notas de nuestros egresados, de las estas últimas cohortes, es de 7.10 puntos; demostrando así, que la Carrera de Medicina de nuestra Facultad no sólo cumple con su plan de estudio en tiempo y forma, sino que agrega excelentes resultados académicos, un profesional con un perfil humanístico, y además de compromiso con la comunidad a la que pertenece. Esta es nuestra experiencia, y ésta es nuestra convicción, Aldous Huxley dice: "Experiencia no es lo que a uno le sucede, sino lo que uno hace con lo que le sucede". 
El mundo de hoy vive una gran vorágine, a la que todos estamos expuestos, en donde la palabra éxito parece ser un sinónimo de sumar actividades a veces sin sentido, en la cual los minutos tienen un precio impuesto por vaya a saber quién, constituyéndose en algo ilusorio disponer de un tiempo para pensar, para escuchar y para atender la angustia de un ser. Parece que pensar, mirar a los ojos y escuchar atentos y con empatía la necesidad comunicacional de una persona problematizada, es considerado una pérdida de tiempo. Éste mis queridos colegas es uno de los desafíos más importantes que enfrenta el médico de hoy.

Así aprender y practicar la comunicación con nuestros pacientes es una condición vital del buen médico. Y esta puede ser una de las grandes diferencias entre un médico cientificista, frío, poco comprometido; a un médico humanizado empapado de las necesidades propias de la sociedad a la que pertenece y con capacidad de cambio o de contención. Esta habilidad comunicacional, no sólo se construye a través del estudio y del conocimiento específico que la ciencia produce, sino de consustanciarse diariamente, minuto a minuto, de todos los mensajes que permanentemente emanan de las personas, de sus expresiones, de sus actitudes, de sus emociones, de sus ojos, de sus manos, pero también de su entorno y de su ambiente; la relación médico paciente es un fecundo intercambio de sensaciones, que busca en uno comprender y en el otro entregar; la relación médico paciente es un acto de máxima confianza. Así, saber comunicarnos en nuestra profesión, con ciencia y con humildad, es conciencia, es ética, es amor al prójimo; es ser médico.

$\mathrm{Y}$ en este camino, con la firme convicción de formar un médico humanizado, nos hemos comprometido en trabajar explícitamente desde la Facultad en valores. Nuestra sociedad está necesitando re-jerarquizar la importancia de trasmitir valores y de comprometernos activamente en desarrollarlos. Los valores son principios que nos permiten orientar nuestro comportamiento, en éste caso de universitarios y como profesionales de la salud. Estos valores nos permitirán formular metas y propósitos en función de lo que hoy nos exige toda la sociedad, nos permitirán fijar actitudes y conductas que nuestros egresados deben portar como característica distintiva de esta cuatri-centenaria universidad. De modo que, profundizar en el humanismo, la ética, el acto de servicio, el compromiso social, la comunicación, la inter-disciplina representada en el respeto al equipo de salud, y la autoformación continua, son nuestro compromiso primordial. Como dice José Saramago "educar es inculcar valores".

Queridos nóveles colegas, se acabó el tiempo de soñar que iban a ser médicos, hoy, ahora y en adelante, lo son y lo serán, esta centenaria universidad lo atestigua. A caminar, a ejercer, a comprometerse, a servir. Vuestra conciencia se los demandará. Es ya la hora de trabajar. Así, sentenció célebremente el escritor Ortega y Gasset: ¡Argentinos, a las cosas, a las cosas!

En nombre de la Facultad: el mejor camino, el mejor destino, la mejor familia. Felicitaciones. Mucha suerte. 